\title{
Patients' perceptions of the impact of ulcerative colitis on social and professional life: results from the UC-LIFE survey of outpatient clinics in Spain
}

This article was published in the following Dove Press journal:

Patient Preference and Adherence

\section{Xavier Calvet ${ }^{1-3}$ \\ Federico Argüelles-Arias ${ }^{4}$ \\ Antonio López-Sanromán ${ }^{5}$ \\ Luis Cea-Calvo ${ }^{6}$ \\ Berta Juliá 6 \\ Cristina Romero de Santos ${ }^{6}$ \\ Daniel Carpio ${ }^{7}$}

'Hospital de Sabadell. Corporació Sanitària Universitària Parc

Taulí, Sabadell, Spain; ${ }^{2}$ Centro de investigación biomédica en red de enfermedades hepáticas y digestivas (CIBEREHD), Spain; ${ }^{3}$ Department of Medicine, Universitat Autònoma de Barcelona, Bellaterra, Spain; ${ }^{4} U G C$ Digestivo Intercentros Hospitales Virgen MacarenaRocío, Seville, Spain; ${ }^{5}$ Section of Gastroenterology, Department of Gastroenterology and Hepatology, Hospital Ramón y Cajal, Madrid, Spain; ${ }^{6}$ Medical Affairs Department, Merck Sharp \& Dohme, Madrid, Spain; ${ }^{7}$ Service of Gastroenterology Complexo Hospitalario Universitario de Pontevedra, Instituto de Investigación Biomedica (IBI), Pontevedra, Spain
Correspondence: Cristina Romero de Santos

Medical Affairs Department, Merck Sharp \& Dohme Spain, Josefa Valcárcel 38, 28027, Madrid, Spain

Tel +34 699453257

Fax +34913210616

Email cristina.rdesantos@merck.com
Purpose: Ulcerative colitis (UC) may cause many patients to miss out on important personal and professional opportunities. We therefore conducted a survey (UC-LIFE) to assess patients' perceptions of the impact of UC on social and professional lives.

Patients and methods: Consecutive unselected UC patients aged $\geq 18$ years were recruited from 38 outpatient clinics in Spain. Patients completed the survey at home, returning it by post. The survey comprised 44 multiple-choice questions, including questions about the impact of UC on social, personal, professional, and academic activities.

Results: Of 585 patients invited, 436 (75\%) returned the survey (mean age 46 years; 47\% women). High proportions of patients considered their disease "sometimes", "frequently" or "mostly/always" influenced leisure activities (65.1\%), recreational or professional activities $(57.6 \%)$, or relationships with relatives or friends (9.9\%). Patients also reported that UC influenced their decision to have children (17.2\%), or their ability to take care of children $(40.7 \%)$; these percentages were higher in women and in younger patients. Overall, $47.0 \%$ of patients declared that UC influenced the kind of job they performed, $20.3 \%$ had rejected a job due to UC, $14.7 \%$ had lost a job due to UC, and $19.4 \%$ had had academic problems due to UC.

Conclusion: Beyond symptoms alone, UC imposes an enormous additional burden on patients' social, professional, and family lives. This extra burden clearly needs to be addressed so that the ultimate goal of IBD treatment - normalization of patient quality of life - can be attained by as many patients as possible.

Keywords: disease burden, patient-reported outcomes, patients' perceptions, quality of life, ulcerative colitis

\section{Introduction}

Ulcerative colitis (UC) is a chronic and idiopathic inflammatory bowel disease (IBD) affecting the mucosal layer of the colon. The degree of mucosal involvement varies from proctitis (only the rectum is affected) to pancolitis (the entire colon is affected). UC is typically diagnosed in early adulthood and clinically characterized by relapsing and remitting symptoms such as diarrhea, rectal bleeding, abdominal pain, fecal urgency, weight loss, and fatigue; in up to one third of patients, these symptoms are accompanied by articular, dermatological, and/or ocular diseases. ${ }^{1,2}$ Although most UC patients present with a mild-to-moderate disease course, about $14 \%-17 \%$ of patients may experience an aggressive course. ${ }^{3}$ These patients may require hospital admission, and up to $19 \%$ of patients with pancolitis will need colectomy, typically during the first 2 years after diagnosis. ${ }^{4}$ Thus, although UC does not reduce life expectancy, it is a markedly disabling disease for a considerable number of patients. $^{5}$ 
UC presents two peaks of incidence: the main one at age 30-40 years, and another one at about 60 years. ${ }^{1}$ Younger patients seem to present with a worse disease course than patients with disease onset after age 60 years. ${ }^{6}$ As UC frequently begins during a stage of life when people develop a professional career and start a family, and together with its hallmark symptoms, chronicity, and relapsing nature, the condition has a substantial impact on patients' lives, in many cases, important personal and professional opportunities may be lost for patients. ${ }^{7-13}$

Globally, the incidence and prevalence of UC have been increasing over time, as have costs associated with the disease. ${ }^{14}$ In Europe, the annual direct and indirect costs related to UC are estimated to be as high as $€ 12.5-29.1$ billion. More than half of this figure is attributable to the indirect cost of absence from paid work, which includes costs associated with sick leave, early retirement, and reduced employment. ${ }^{15}$

Because the burden of UC surpasses clinical symptoms alone, we considered it interesting to collect information directly from patients through a cross-sectional survey (UC-LIFE) about their perception of how UC affects various aspects of their everyday lives. The survey characteristics and several outcomes have been published previously. ${ }^{16-18}$ Herein, we present insights from the UC-LIFE survey about the impact of UC on the social and professional lives of Spanish patients followed in outpatient clinics.

\section{Patients and methods}

\section{Ethics approval}

The study was reviewed and approved by the Clinical Investigation Ethics Committee of the Parc Taulí Hospital, Barcelona, Spain. The survey documentation included printed instructions and information for patients about the anonymous nature of the survey and aggregated data processing which ensured that patient identification was not possible. Given that no identifiable information was collected, and as accepted by the Clinical Investigation Ethics Committee, no signed informed consent was requested, the voluntary return of completed questionnaires was taken as implied consent to participate in the study.

A detailed description of the UC-LIFE survey, subjects, and procedures has been published previously. ${ }^{16-18} \mathrm{~A}$ brief summary of study methodology, participants, and procedures is provided in the following section.

Unselected patients aged $\geq 18$ years with UC who were attending one of 38 representative hospital gastroenterology clinics throughout Spain were recruited consecutively for the study and handed the survey.
At-home completion of the survey was voluntary and anonymous, with no collection of clinical data; invited patients received no reminders to complete the survey.

The UC-LIFE survey consisted of 44 multiple-choice questions regarding details about patient demographics; perceptions about the burden associated with UC symptoms and severity; the emotional burden of the disease in terms of daily life and other aspects described previously. ${ }^{16-18}$ Specifically, the survey included questions about the impact of UC on social, personal, professional, and academic activities of patients, and about the influence of UC on childcare. These questions were formulated with wording based on physician and patient recommendations. Several questions included a Likert scale ranging from "never" to "mostly/always", while others were answered as "yes" or "no". The full questionnaire is available as supplemental content to the main publication: http://links.lww.com/EJGH/A110. ${ }^{16}$

Due to the exploratory and descriptive nature of the survey, there was no formal statistical hypothesis or pre-determined sample size. Mean and SDs were used to describe quantitative variables or, if data were not distributed normally, median and interquartile range (IQR) were used. Frequencies or percentages were used for nominal or ordinal variables. Proportional data (eg, gender, age, disease duration, burden of symptoms during the previous year) were compared using the Chisquared or Fisher exact tests. Multiple subgroup comparisons were performed using the least significant differences test. Statistical significance was considered for $P$-values $\leq 0.05$. Statistical analyses were conducted using SPSS software (version 18.0.0; SPSS Inc., Chicago, IL, USA).

\section{Results}

\section{Demographic data}

Thirty-nine physicians handed out the survey to $585 \mathrm{UC}$ patients, and 436 patients returned the questionnaire (response rate $74.5 \%$ ). Due to the anonymous nature of the survey, the profile of non-responding patients is unknown. Responders had a mean age of 46.2 (SD 13.6) years, $52.8 \%$ were men, and the median duration of UC was 8 years (IQR 4-15). Sixty-nine percent of patients were married or had a partner, and $52.7 \%$ were active workers. When asked about perceived symptom burden during the previous year, $47.1 \%$ of patients reported "symptoms controlled", and $28.0 \%$ and $24.9 \%$, respectively, reported "symptoms not impairing everyday life" or "symptoms impairing everyday life".

\section{Impact of UC on social and family life}

Figure 1 depicts the responses of patients to statements about how they perceived the impact of UC on their social lives. 


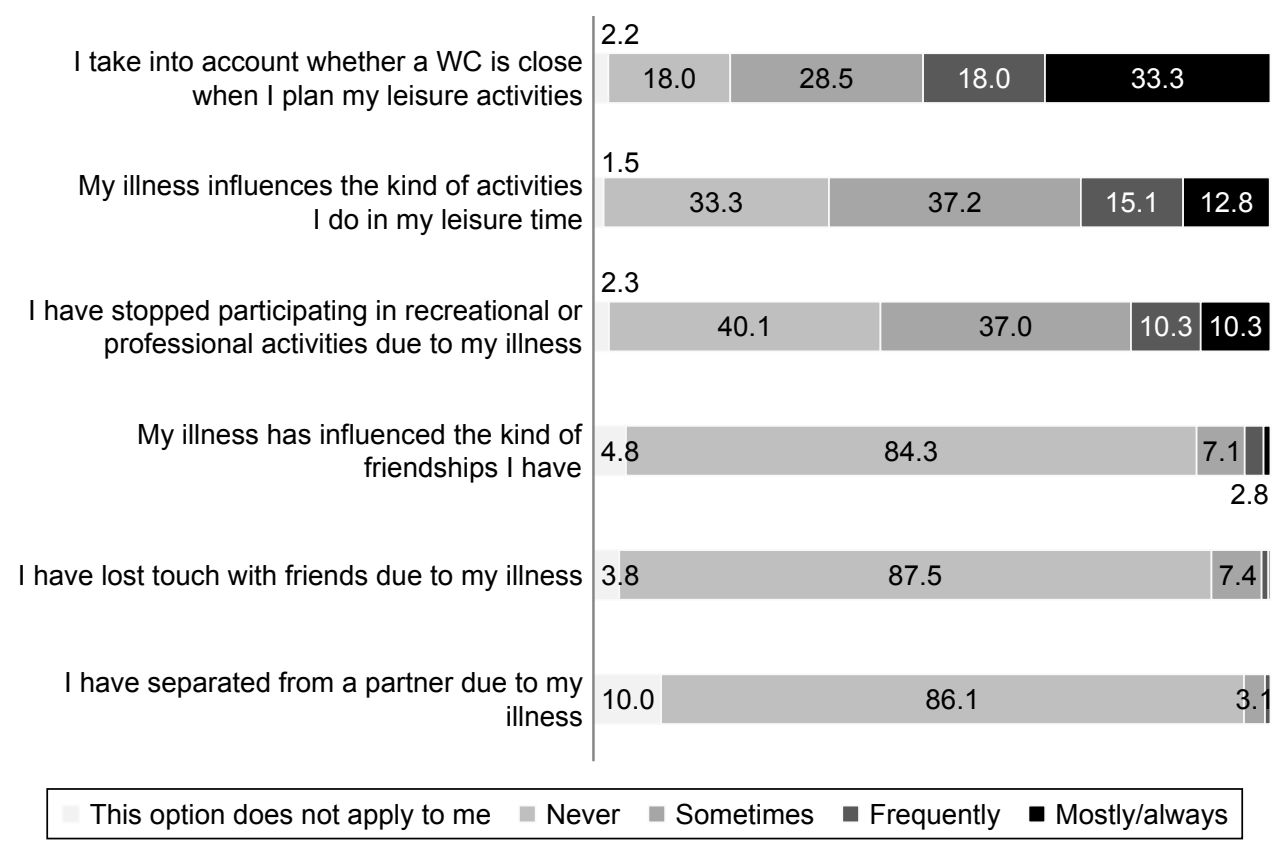

Figure I Patients' responses to statements about the impact of ulcerative colitis on their social lives.

Note: numbers within the figure are percentages.

Abbreviation: WC, water closet.

A high proportion of patients considered their disease "sometimes", "frequently" or "mostly/always" influenced leisure activities ( $65.1 \%$ of patients), recreational or professional activities $(57.6 \%)$, or relationships with relatives or friends $(9.9 \%)$. For several statements related to leisure activities, the percentage of patients who responded "frequently" or "mostly/always" was significantly higher in patients who perceived more severe UC-related symptoms (Table 1). Nonetheless, substantial proportions of patients who described their UC-related symptoms as "controlled" or "present but not impairing everyday life" still responded "frequently" or "mostly/always" to questions about leisure activities: for example, $32.0 \%$ of patients with symptoms "controlled" and $52.3 \%$ of those with symptoms "present but not impairing everyday life" responded "frequently" or "mostly/always" to the statement "I take into account whether a WC is close when I plan my leisure activities". The frequencies of responses were similar by tertiles of age and disease duration (data not shown), but frequencies of a "frequently" or "mostly/always" response to several statements were slightly higher in women than in men (Figure 2).

Patients were asked about the impact of UC on their decision to have children and their ability to take care of children (Table 2). Excluding patients who responded that these questions did not apply to them $(n=126$ and $n=147$, respectively), 48 of 278 patients ( $17.2 \%$ overall: $7.4 \%$ of men; $28.4 \%$ of women) reported that UC had influenced their decision to have children, and 104 of 255 patients ( $40.7 \%$ overall: $30.0 \%$ of men; $52.0 \%$ of women) agreed that UC influenced their ability to take care of children. The percentages of

Table I Proportion a patients who responded "frequently" or "mostly/always" to questions about their social lives

\begin{tabular}{|c|c|c|c|c|c|}
\hline Have you ever been in any of the following situations? & Total & $\begin{array}{l}\text { Controlled } \\
\text { symptoms }\end{array}$ & $\begin{array}{l}\text { Symptoms } \\
\text { not impairing } \\
\text { everyday life }\end{array}$ & $\begin{array}{l}\text { Symptoms } \\
\text { impairing } \\
\text { everyday life }\end{array}$ & P-value \\
\hline $\begin{array}{l}\text { I take into account whether a WC is close when I plan my } \\
\text { leisure activities }\end{array}$ & $211(51.3)$ & $57(32.0)$ & $56(52.3)$ & $80(83.3)$ & $<0.001$ \\
\hline My illness influences the kind of activities I do in my leisure time & $109(27.9)$ & $21(12.6)$ & $24(23.1)$ & $58(6 \mid .7)$ & $<0.001$ \\
\hline $\begin{array}{l}\text { I have stopped participating in recreational or professional } \\
\text { activities due to my illness }\end{array}$ & $80(20.6)$ & $14(8.4)$ & $17(16.4)$ & $46(49.4)$ & $<0.001$ \\
\hline My illness has influenced the kind of friendships I have & $15(3.8)$ & $4(2.4)$ & $3(2.8)$ & $6(6.4)$ & 0.213 \\
\hline I have lost touch with friends due to my illness & $5(1.3)$ & $2(1.2)$ & I (0.9) & $2(2.1)$ & 0.746 \\
\hline I have separated from a partner due to my illness & $3(0.8)$ & $\mathrm{I}(0.6)$ & $0(0.0)$ & $2(2.2)$ & 0.502 \\
\hline
\end{tabular}

Notes: aData shown are number (\%) of patients. Because some patients did not respond to the perceived symptomatic burden of UC question, the sum of the different options does not always match the total number.

Abbreviations: ns, not significant; UC, ulcerative colitis; WC, water closet. 


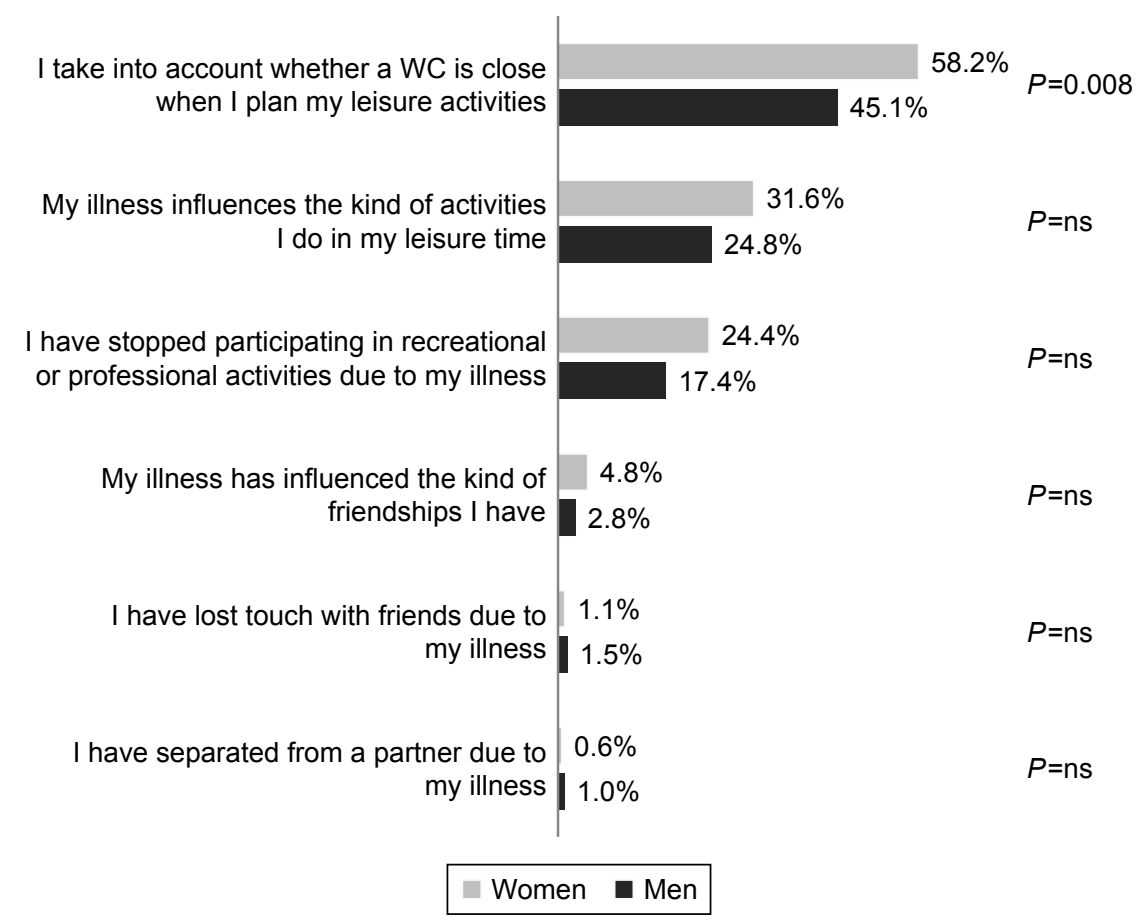

Figure 2 Percentages of men and women who responded "frequently" or "mostly/always" to statements about the impact of ulcerative colitis on their social lives. Abbreviations: ns, not significant; WC, water closet.

patients reporting this negative impact of UC were statistically significantly greater in women than in men, in younger patients (aged $\leq 38$ years), and in patients who reported that symptoms impaired everyday life (Table 2).

Table 2 Proportion (\%) of patients who responded "yes" to questions about childcare ${ }^{a}$

\begin{tabular}{|c|c|c|c|c|}
\hline \multirow[t]{2}{*}{ Characteristic } & \multicolumn{2}{|c|}{$\begin{array}{l}\text { Has UC } \\
\text { influenced your } \\
\text { decision to } \\
\text { have children? }\end{array}$} & \multicolumn{2}{|c|}{$\begin{array}{l}\text { If you have } \\
\text { children, does UC } \\
\text { influence your } \\
\text { ability to take } \\
\text { care of them? }\end{array}$} \\
\hline & Yes & $P$-value & Yes & $P$-value \\
\hline Gender & & $<0.001$ & & $<0.001$ \\
\hline Men & 7.4 & & 30.0 & \\
\hline Women & 28.4 & & 52.0 & \\
\hline Age & & $<0.001$ & & 0.013 \\
\hline$\leq 38$ years & 28.4 & & 48.9 & \\
\hline$>38-52$ years & 18.6 & & 47.2 & \\
\hline$>52$ years & 0.3 & & 26.7 & \\
\hline UC duration & & 0.860 & & 0.190 \\
\hline $0-5$ years & 18.9 & & 34.8 & \\
\hline$>5-12$ years & 20.8 & & 48.1 & \\
\hline$>12$ years & 17.6 & & 37.0 & \\
\hline Perceived symptom burden & & 0.009 & & $<0.001$ \\
\hline Controlled & 15.2 & & 22.4 & \\
\hline Not impairing everyday life & 11.9 & & 36.6 & \\
\hline Impairing everyday life & 30.7 & & 65.2 & \\
\hline
\end{tabular}

Notes: Data shown are percentages of patients. ${ }^{\text {aExcluding patients who responded }}$ that these questions did not apply to them ( $n=126$ and $n=147$, respectively).

Abbreviation: UC, ulcerative colitis.

\section{Impact of UC on professional and academic life}

Patients were asked to respond "yes/no" to five different statements about their professional and academic lives. Between $13 \%$ and $20 \%$ of patients responded that questions about working life did not apply to them; one third of patients considered that questions about academic life did not apply to them. Excluding these patients, an overall negative impact of UC on professional and academic factors was described, as exemplified by $47.0 \%$ of patients declaring that UC influenced the kind of job they performed, $63.7 \%$ reporting sick leave due to UC, and $19.4 \%$ considering that they had had problems in pursuing their studies due to UC (Table 3). Percentages were similar in men and women but were greater in patients who had reported symptoms during the previous year, especially if symptoms had impaired everyday life (Figure 3). Patients with longer disease duration described episodes of sick leave more frequently $(52.5 \%, 73.5 \%$, and $68.4 \%$ of patients with UC duration $<5,5-12$, and $>12$ years, respectively; $P=0.005$ ), with no influence of disease duration on the other statements. The percentages of patients who reported having lost a job or having had problems in pursuing their studies due to UC were significantly greater in the younger age group (aged $\leq 38$ years; Figure 4 ). 
Table 3 Proportion a of patients who responded "yes" to questions about professional or academic factors ${ }^{\mathrm{b}}$

\begin{tabular}{|c|c|c|c|c|}
\hline Have you ever been in any of the following situations? & Total & Men & Women & $P$-value \\
\hline I have had sick leave due to my UC & $214(63.7)$ & I2I (65.4) & $93(61.6)$ & 0.469 \\
\hline My illness has influenced the kind of job I perform & $162(47.0)$ & $88(47.8)$ & $74(47.0)$ & 0.729 \\
\hline I have rejected a job due to my UC & $60(20.3)$ & $26(16.7)$ & $34(24.3)$ & 0.104 \\
\hline I have had problems with my studies due to my UC & $44(19.4)$ & $16(14.7)$ & $28(23.7)$ & 0.319 \\
\hline I have lost a job due to my UC & $43(14.7)$ & $26(16.6)$ & $17(12.6)$ & 0.340 \\
\hline I have had to leave my studies due to my UC & $12(5.5)$ & $4(3.8)$ & $8(6.9)$ & 0.319 \\
\hline
\end{tabular}

Notes: a Data shown are number (\%) of patients. ${ }^{\circ}$ Excluding patients who responded that these questions did not apply to them.

Abbreviation: UC, ulcerative colitis.

\section{Discussion}

The principal findings of this large, cross-sectional survey are the significant, patient-perceived burdens of $\mathrm{UC}$ on social and family life, and on professional and academic life. These findings are of considerable relevance for several reasons: first, these kinds of findings are not frequently reported from large populations, and even less frequently directly from patients, with no physician intervention or interpretation. Second, we provided a comprehensive description of the social and professional impact of the disease and described a link to disease activity as perceived by the patient. Finally, these specific impacts are evident even in patients who reported that their symptoms were "controlled", which is something that merits special attention. High proportions of patients reported that UC markedly influenced leisure activities and relationships with relatives or friends. This applied even in patients who reported that symptoms were "controlled" or "not impairing daily life". Substantial proportions of patients also reported that UC had influenced their decision to have children, or their ability to look after children. These proportions were significantly greater in younger patients, and patients with a high perceived symptom burden. Regarding professional and academic life, almost half of patients reported that UC influenced the job they performed, almost two thirds documented sick leave due to UC, and almost one fifth reported difficulties in pursuing their studies because of UC. A significantly

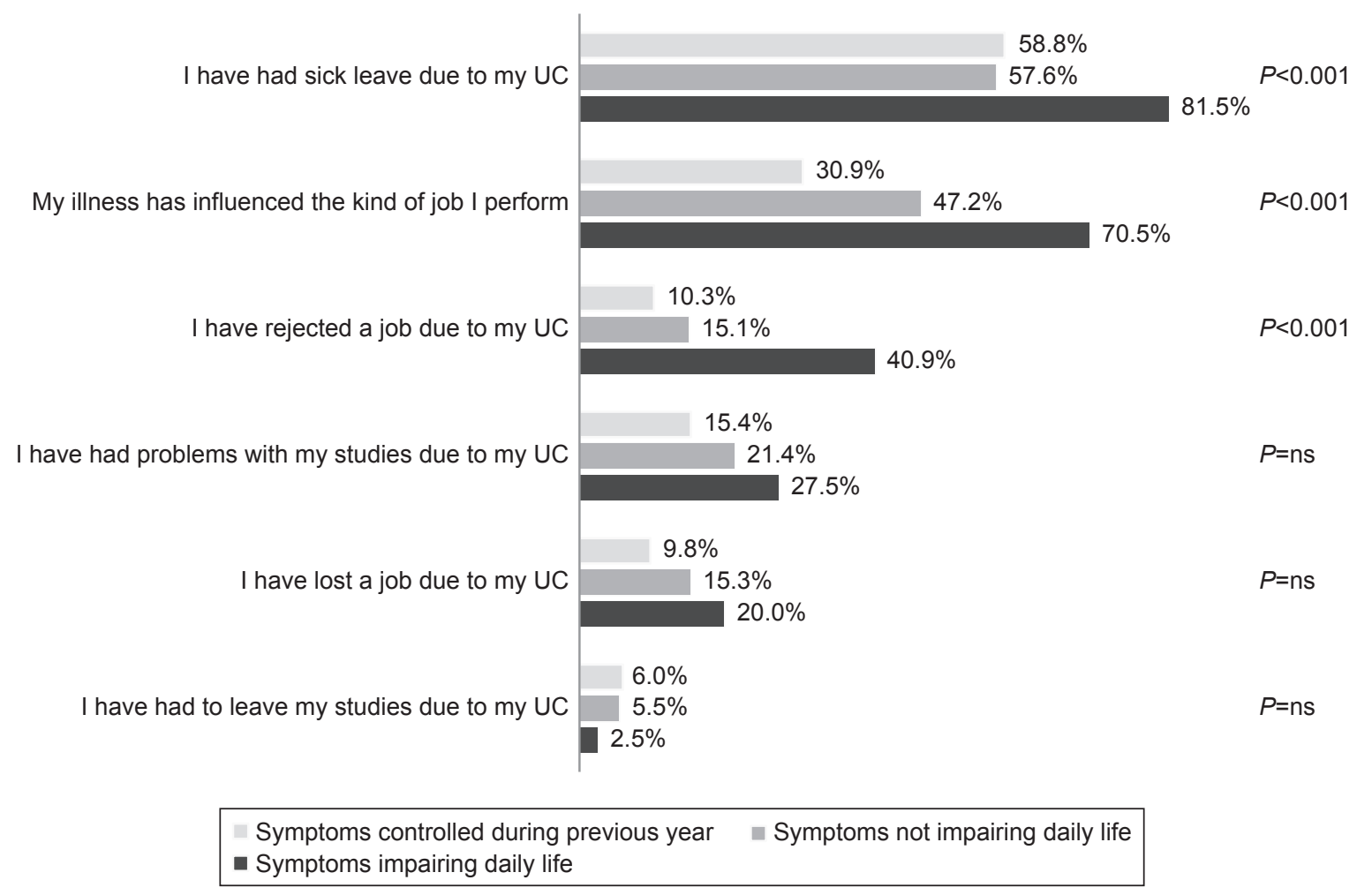

Figure 3 Percentages of patients who responded "yes" to statements about the impact of ulcerative colitis on professional and academic life (stratified by perception of symptomatic burden).

Abbreviations: ns, not significant; UC, ulcerative colitis. 


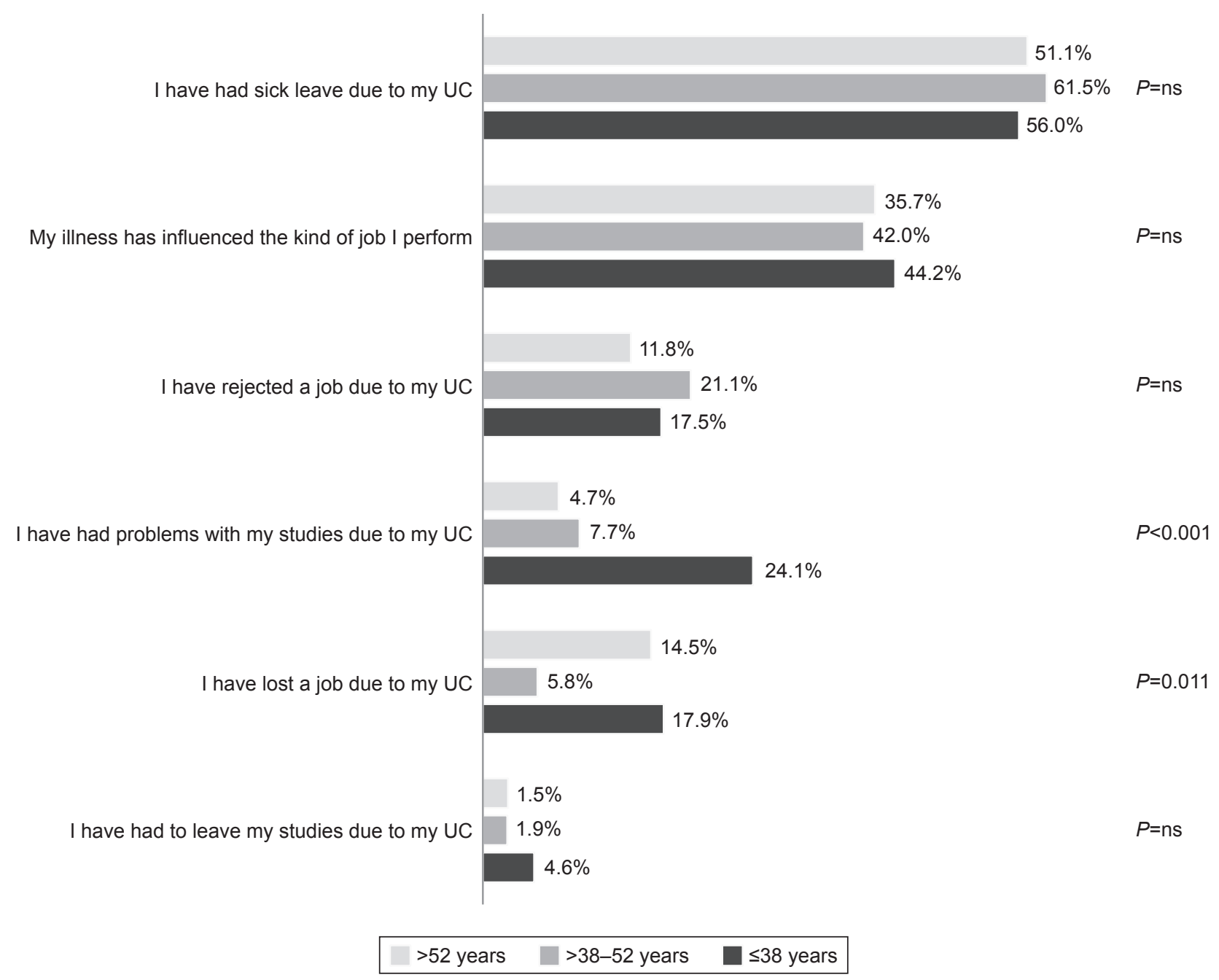

Figure 4 Percentages of patients who responded "yes" to statements about the impact of ulcerative colitis on professional and academic life (stratified by age [tertiles]). Abbreviations: ns, not significant; UC, ulcerative colitis.

greater proportion of younger patients compared to older patients had lost a job because of UC or had experienced study problems due to UC.

Particular strengths of the current survey are its ability to glean real-world evidence from the patient perspective and obtain broader knowledge of the overall impact of UC on patient quality of life (QoL). This is particularly pertinent given the ever-increasing focus on patient-reported outcomes in IBD, ${ }^{16,19}$ and the increasing recognition of often divergent goals of physicians and IBD patients. In fact, it has been described previously that the most desirable goals for patients are often symptom control and normalization of QoL, ${ }^{16,19}$ goals that must be attained together with the histological goal of complete mucosal healing. Indeed, the continuous control of symptoms in UC patients has been associated with long-term steroid-free remission, endoscopic remission, and mucosal healing, ${ }^{20}$ but minimizing the impact of $\mathrm{UC}$ on patients' social and professional life must also be taken into account as a patient goal. Attaining both physicians' and patients' goals might therefore be the optimal objective in achieving complete UC clinical control.

We have previously described that the prevalence of specific UC symptoms was substantial even among patients who had defined their symptoms as "controlled" ${ }^{16}$ suggesting that patients could accept some degree of living with troublesome symptoms as "normal". In the current work, we extended this finding to several effects of UC on social and professional life: patients who considered their symptoms to be "controlled" also described frequent limitations with regard to social and professional life. In failing to realize the full therapeutic potential of treatment, many patients may fail to attain the maximum possible QoL improvements. Even in the presence of endoscopic and symptomatic cure, many IBD patients do not attain normalization of QoL. ${ }^{21,22}$ These patients may be 
more likely to experience problems with fatigue, anxiety, depression, deteriorating treatment adherence, and increased work disability. ${ }^{8,21,23} \mathrm{~A}$ direct consequence will likely be an increased overall use of health care resources. ${ }^{21}$

Our survey, in highlighting the major scale of disease burden posed by UC, endorses other study findings. Regarding family life, for instance, the extent of misperception about IBD and fertility is broadly recognized. A Mediterraneanregion study reported that more than $60 \%$ of women with IBD were fearful that their disease and treatment might lead to a complicated pregnancy and fetal damage. ${ }^{11}$ An Australian study also outlined that, after a diagnosis of IBD, three quarters of women were worried about passing the disease to their offspring, about half were worried about infertility, and approximately one third considered not having children. ${ }^{12}$ Other researchers corroborated that "voluntary" childlessness in IBD patients may result from apparently unjustified concerns about detrimental reproductive outcomes. ${ }^{13}$

Regarding the impact of IBD on social life and leisure activities, our survey found that, even in patients with symptoms reported as "controlled" or "not impairing daily life", the disease had a marked negative influence on several aspects of social life: $32 \%$ and $52 \%$ of those patients, respectively, reported the need for a nearby $\mathrm{WC}$ when planning leisure activities; $13 \%$ and $23 \%$, respectively, expressed that IBD influenced the type of activity undertaken; and $8 \%$ and $16 \%$, respectively, indicated that they had stopped participating in recreational or professional activities because of IBD. These findings are in line with data from the initial UC-LIFE publication, ${ }^{16}$ which revealed that patients who considered their symptoms "controlled/nearly controlled" still experienced a marked prevalence of some symptoms: diarrhea, urgency, rectal bleeding, flatulence, fatigue, abdominal pain, and joint pain. Moreover, the UC-LIFE survey showed that high symptom burden during the previous year (ie, "symptoms impairing everyday life") had a significant influence on all evaluated aspects of patients' social, personal, and professional lives. This clearly underscores the suggestion that attainment of symptom control in UC patients is an essential first step toward true normalization of QoL.

Our survey findings of a markedly deleterious effect of IBD on various aspects of professional and academic life are clearly in agreement with data from large surveys ${ }^{24}$ systematic reviews, ${ }^{10}$ and other trials. ${ }^{8,9,25}$ For example, in a large European survey in $>4,500$ IBD patients, most patients reported that their disease had caused absence from work, and $45 \%$ commented that IBD had a negative impact on educational performance. ${ }^{24}$ Moreover, in a study of IBD patients at a Dutch outpatient clinic, de Boer et al documented that $25 \%$ of employed patients were on sick leave, about one quarter were receiving a disability pension, and approximately three quarters had work-related difficulties such as concentration problems and slow work pace. ${ }^{8}$ A lack of paid employment was associated with worse QoL and greater rates of anxiety and depression. ${ }^{8}$

Another interesting finding in our survey was the major impact of age on work and academic performance: notably, among patients aged $\leq 38$ years, $18 \%$ reported that UC had caused them to lose their job, and 24\% reported that UC had caused study problems. Speculation suggests that such high rates of work loss and study impairment in young patients may be linked with increased rates of psychological and psychiatric morbidity (eg, anxiety, depression). ${ }^{26,27}$

While it is difficult to accurately quantify the holistic burden of UC on social and professional life, the UC-LIFE survey is a significant step in this direction, and its findings highlight the need to tackle the consequences of UC not only from medical, but also from social perspectives. However, the study has some limitations: ${ }^{16}$ data were derived from patient self-assessment of symptoms during the previous year and may therefore have been confounded by recall bias; and some degree of selection bias was present, since the survey was distributed through hospital outpatient clinics, and the population did not truly reflect the overall UC population. Thus, study findings from these selected patient groups in Spain are not necessarily applicable to other geographical areas and to broader populations of UC patients. Nevertheless, only when efforts have been made to quantify the full impact of UC on QoL, including on aspects beyond straightforward symptom control (ie, on aspects of social, professional, and family lives), can attempts be made to fully normalize QoL in UC patients. Future studies, using objective, well-validated measures, are now warranted to more clearly define the impact of UC on QoL, and the effects of treatment and improved adherence to treatment in normalizing QoL in UC patients.

\section{Conclusion}

The insights from patients presented here underscore how UC can influence many aspects of patients' everyday lives, including social and family activities and relationships, and freedom to enjoy leisure time and participate in professional and academic activities; UC can also have a major bearing on potentially life-changing decisions for patients, such as which type of employment to pursue, or whether or not to have children. These aspects are seldom considered or addressed in 
studies and are difficult to quantify, but impose an enormous extra burden on patients, well beyond UC symptoms alone. Such aspects of patients' social, professional, and family lives clearly need to be addressed, in line with patient-centered approaches to UC management, so that the ultimate goal of IBD treatment - normalization of patient QoL - can be attained by as many patients as possible.

\section{Acknowledgments}

The authors wish to thank Alejandro Pedromingo (Bioestadística, Madrid, Spain). Medical writing assistance was provided by David Murdoch and David P Figgitt PhD, ISMPP CMPPтм, Content Ed Net, and funded by Merck Sharp \& Dohme Spain.

The authors wish to thank the patients for their contribution in filling out printed surveys, and the following gastroenterologists (in alphabetical order) for contributing to the work by distributing surveys to patients: Dr María M Alcalde, Hospital Universitario Infanta Cristina, Badajoz; Dr Xavier Aldeguer, Hospital Universitario Doctor Josep Trueta, Gerona; Dr Federico Argüelles-Arias, Hospital Universitario Virgen Macarena, Sevilla; Dr Maite Arroyo, Hospital Universitario Lozano Blesa, Zaragoza; Dr Nelly Balza, Hospital Son Llàtzer, Mallorca; Dr Jesús Barrio, Hospital Universitario Río Hortega, Valladolid; Mrs Olga Benítez, Hospital Universitario Mútua de Terrassa, Barcelona; Dr Fernando Bermejo, Hospital Universitario de Fuenlabrada, Madrid; Dr José L Cabriada, Hospital de Galdakao,Vizcaya; Dr Xavier Calvet, Corporación Sanitaria Universitaria Parc Taulí, Barcelona; Dr Raquel Camargo, Hospital Universitario Virgen de la Victoria, Málaga; Dr Daniel Carpio, Complejo Hospitalario Universitario de Pontevedra, Pontevedra; Dr María L Castro, Hospital Universitario Virgen Macarena, Sevilla; Dr Daniel Ceballos, Hospital Universitario Doctor Negrín, Gran Canaria; Dr Cristobal de la Coba, Hospital de Cabueñes, Asturias; Dr Xavier Cortés, Hospital de Sagunto, Valencia; Dr Eugeni Domènech, Hospital Universitario Germans Trias i Pujol, Barcelona; Dr Carmen Dueñas, Hospital San Pedro de Alcántara, Cáceres; Dr María Fe García, Hospital Universitario de Elche, Alicante; Dr Santiago García, Hospital Universitario Miguel Servet, Zaragoza; Dr Valle García, Hospital Universitario Reina Sofia, Córdoba; Dr Rosario Gómez, Hospital Universitario Virgen de las Nieves, Granada; Dr Pedro González, Complejo Hospitalario La Mancha Centro, Ciudad Real; Dr Jordi Guardiola, Hospital Universitario de Bellvitge, Barcelona; Dr Álvaro Hernández, Hospital de Torrecárdenas, Almería; Dr Esteban Hernández, Hospital Universitario del Henares, Madrid; Dr José M
Huguet, Consorcio Hospital General Universitario de Valencia, Valencia; Dr Antonio López-Sanromán, Hospital Universitario Ramón y Cajal, Madrid; Dr Pilar Martínez, Hospital Universitario 12 de Octubre, Madrid; Dr Teresa Martínez, Hospital Rafael Méndez, Murcia; Dr Ana Muñagorri, Hospital Universitario de Donostia, San Sebastián; Dr Concepción Muñoz, Hospital Virgen de la Salud, Toledo; Dr José F Muñoz, Hospital Clínico Universitario de Salamanca, Salamanca; Dr Héctor Pallarés, Hospital Juan Ramón Jiménez, Huelva; Dr Laura Ramos, Hospital Universitario La Laguna, Tenerife; Dr Montserrat Rivero, Hospital Universitario Marqués de Valdecilla; Cantabria; Dr Antonio Rodríguez, Hospital Clínico Universitario de Salamanca, Salamanca; Dr Cristina Rodríguez, Complejo Hospitalario de Navarra, Navarra; Dr Patricia Romero, Hospital General Universitario Santa Lucia, Murcia.

This project was financed by Merck Sharp \& Dohme Spain, a subsidiary of Merck \& Co, Whitehouse Station, New Jersey, USA, and is endorsed by the Spanish Association of Patients with Crohn's Disease and Ulcerative Colitis.

\section{Disclosure}

$\mathrm{X}$ Calvet has served as speaker, consultant and advisor, or has received funding for research, from Merck Sharp \& Dohme, AbbVie, Hospira, Pfizer, Faes Farma, Shire Pharmaceuticals, Gebro Pharma, Otsuka Pharmaceutical, and Vifor Pharma. F Argüelles-Arias has served as speaker, consultant and advisor, or has received funding for research, from Merck Sharp \& Dohme, AbbVie, Takeda, Tillotts, Kern-Pharma, Faes Farma, Shire Pharmaceuticals, Gebro Pharma, and Vifor Pharma. A López-Sanromán has served as speaker, consultant or advisor for Merck Sharp \& Dohme, AbbVie, Hospira, Gebro Pharma, Faes Farma, Shire Pharmaceuticals, Takeda, and Tillotts. L Cea-Calvo, B Juliá, and C Romero de Santos are full-time employees in the Medical Affairs Department, Merck Sharp \& Dohme Spain. D Carpio has served as consultant to Merck Sharp \& Dohme, AbbVie, Pfizer, and UCB Pharma, has received payment as speaker from Merck Sharp \& Dohme, AbbVie, Pfizer, Takeda, Shire, Gebro Pharma, Tillotts, Dr Falk Pharma, and Almirall, and has been involved in clinical research with Merck Sharp \& Dohme, AbbVie, and Tygenix. The authors report no other conflicts of interest in this work.

\section{References}

1. Ungaro R, Mehandru S, Allen PB, Peyrin-Biroulet L, Colombel JF. Ulcerative colitis. Lancet. 2017;389(10080):1756-1770.

2. Marín-Jiménez I, García Sánchez V, Gisbert JP, et al. Immune-mediated inflammatory diseases in patients with inflammatory bowel disease. Baseline data from the Aquiles study. Gastroenterol Hepatol. 2014;37(9): 495-502. 
3. Fumery M, Singh S, Dulai PS, Gower-Rousseau C, Peyrin-Biroulet L, Sandborn WJ. Natural history of adult ulcerative colitis in populationbased cohorts: A systematic review. Clin Gastroenterol Hepatol. 2018; 16(3):343-356.

4. Magro F, Rodrigues A, Vieira AI, et al. Review of the disease course among adult ulcerative colitis population-based longitudinal cohorts. Inflamm Bowel Dis. 2012;18(3):573-583.

5. Peyrin-Biroulet L, Cieza A, Sandborn WJ, et al. Development of the first disability index for inflammatory bowel disease based on the international classification of functioning, disability and health. Gut. 2012;61(2):241-247.

6. Charpentier C, Salleron J, Savoye G, et al. Natural history of elderlyonset inflammatory bowel disease: a population-based cohort study. Gut. 2014;63(3):423-432.

7. Marri SR, Buchman AL. The education and employment status of patients with inflammatory bowel diseases. Inflamm Bowel Dis. 2005; 11(2):171-177.

8. de Boer AG, Bennebroek Evertsz' F, Stokkers PC, et al. Employment status, difficulties at work and quality of life in inflammatory bowel disease patients. Eur J Gastroenterol Hepatol. 2016;28(10): $1130-1136$.

9. Vester-Andersen MK, Prosberg MV, Vind I, Andersson M, Jess T, Bendtsen F. Low risk of unemployment, sick leave, and work disability among patients with inflammatory bowel disease: A 7-year follow-up study of a Danish inception cohort. Inflamm Bowel Dis. 2015;21(10): 2296-2303.

10. Büsch K, da Silva SA, Holton M, Rabacow FM, Khalili H, Ludvigsson JF. Sick leave and disability pension in inflammatory bowel disease: a systematic review. J Crohns Colitis. 2014;8(11):1362-1377.

11. Ellul P, Zammita SC, Katsanos KH, et al. Perception of reproductive health in women with inflammatory bowel disease. J Crohns Colitis. 2016;10(8):886-891.

12. Selinger CP, Eaden J, Selby W, et al. Inflammatory bowel disease and pregnancy: lack of knowledge is associated with negative views. J Crohns Colitis. 2013;7(6):e206-e213.

13. Mountifield R, Bampton P, Prosser R, Muller K, Andrews JM. Fear and fertility in inflammatory bowel disease: a mismatch of perception and reality affects family planning decisions. Inflamm Bowel Dis. 2009; 15(5):720-725.

14. Molodecky NA, Soon IS, Rabi DM, et al. Increasing incidence and prevalence of the inflammatory bowel diseases with time, based on systematic review. Gastroenterology. 2012;142(1):46-54.
15. Cohen RD, Yu AP, Wu EQ, Xie J, Mulani PM, Chao J. Systematic review: the costs of ulcerative colitis in Western countries. Aliment Pharmacol Ther. 2010;31(7):693-707.

16. Carpio D, López-Sanromán A, Calvet X, et al. Perception of disease burden and treatment satisfaction in patients with ulcerative colitis from outpatient clinics in Spain: UC-LIFE survey. Eur J Gastroenterol Hepatol. 2016;28(9):1056-1064.

17. López-Sanromán A, Carpio D, Calvet X, et al. Perceived emotional and psychological impact of ulcerative colitis on outpatients in Spain: UC-LIFE survey. Dig Dis Sci. 2017;62(1):207-216.

18. Argüelles-Arias F, Carpio D, Calvet X, et al. Knowledge of disease and access to a specialist reported by Spanish patients with ulcerative colitis. UC-LIFE survey. Rev Esp Enferm Dig. 2017;109(6):421-429.

19. Casellas F, Herrera-de Guise C, Robles V, Navarro E, Borruel N. Patient preferences for inflammatory bowel disease treatment objectives. Dig Liver Dis. 2017;49(2):152-156.

20. Reinisch W, Colombel JF, Gibson PR, et al. Continuous clinical response is associated with a change of disease course in patients with moderate to severe ulcerative colitis treated with golimumab. Inflamm Bowel Dis. Epub 2018 July 6.

21. Casellas F, Barreiro de Acosta M, Iglesias M, et al. Mucosal healing restores normal health and quality of life in patients with inflammatory bowel disease. Eur J Gastroenterol Hepatol. 2012;24(7):762-769.

22. Casellas F, Robles V, Borruel N, et al. Restoration of quality of life of patients with inflammatory bowel disease after one year with antiTNF $\alpha$ treatment. J Crohns Colitis. 2012;6(9):881-886.

23. Romberg-Camps MJ, Bol Y, Dagnelie PC, et al. Fatigue and healthrelated quality of life in inflammatory bowel disease: results from a population-based study in the Netherlands: the IBD-South Limburg cohort. Inflamm Bowel Dis. 2010;16(12):2137-2147.

24. Lönnfors S, Vermeire S, Greco M, Hommes D, Bell C, Avedano L. IBD and health-related quality of life - discovering the true impact. J Crohns Colitis. 2014;8(10):1281-1286.

25. Kim YS, Jung SA, Lee KM, et al. Impact of inflammatory bowel disease on daily life: an online survey by the Korean Association for the Study of Intestinal Diseases. Intest Res. 2017;15(3):338-344.

26. Mckee-Ryan F, Song Z, Wanberg CR, Kinicki AJ. Psychological and physical well-being during unemployment: a meta-analytic study. $J$ Appl Psychol. 2005;90(1):53-76.

27. Burns JM, Andrews G, Szabo M. Depression in young people: what causes it and can we prevent it? Med J Aust. 2002;177 Suppl: S93-S96.
Patient Preference and Adherence

\section{Publish your work in this journal}

Patient Preference and Adherence is an international, peer-reviewed, open access journal that focuses on the growing importance of patient preference and adherence throughout the therapeutic continuum. Patient satisfaction, acceptability, quality of life, compliance, persistence and their role in developing new therapeutic modalities and compounds to optimize

\section{Dovepress}

clinical outcomes for existing disease states are major areas of interest for the journal. This journal has been accepted for indexing on PubMed Central. The manuscript management system is completely online and includes a very quick and fair peer-review system, which is all easy to use. Visit http://www. dovepress.com/testimonials.php to read real quotes from published authors. 